\title{
Evolution of Psychotherapy 2017: Quick review of the conference
}

\author{
Ulkar Isayeva \\ Khazar University, Baku, Azerbaijan
}

On December $13-17^{\text {th }}, 2017$, the $8^{\text {th }}$ Evolution of Psychotherapy Conference took place in Anaheim, California. The conference takes place every 45 years and is considered the largest conference ever held on the topic of psychotherapy. The first Evolution of Psychotherapy Conference was held in 1985 as a celebration of the $100^{\text {th }}$ birthday of psychotherapy was called as "the Woodstock of Psychotherapy" by TIME magazine. The conference was also covered by The New York Times and Los Angeles Times. Names such as Carl Rogers, Albert Ellis, Carl Jung, Alfred Adler, Jay Haley, James Masterson, and Virginia Satir were members of the first faculty of The Evolution of Psychotherapy Conference in 1985. Since then the conference hosted honorable faculty members such as Albert Bandura, David Marlow, Aaron Beck, Salvador Minuchin, Claudia Black, Deepak Chopra, Otto F. Kernberg, Cloe Madanes, Paul Ekman, Donald Meichenbaum, Christine A.Padesky, Robert Sapolsky, Irvin Yalom and many others. The conference usually draws about 6000-7000 participants who represent every state in the U.S. and more than 50 countries of the world.

I have attended last three Evolution of Psychotherapy conferences, and I find this conference highly useful not only for learning new developments in psychology and other fields, but also for meeting a lot of interesting people and networking. It is also worth mentioning that not only psychologists or psychotherapists, but also representatives and professionals of many other fields were presenting their works during the conference. As much as I would like to talk about all of interesting and important events that took place at the conference, in this article I will be able to cover few of the interesting ones I attended.

The Evolution of Psychotherapy Conference, 2017, consisted of preconference program, large amount of workshops, debates, clinical demonstrations, topical panels, conversation hours, speeches, keynote speakers, and post- 
conference program. Pre-conference program included lectures given by Robert Sapolsky, Michael Yapko, Daniel Amen, Steve Frankel, and David White.

Robert Sapolsky, who has a PhD degree in Neuroendocrinology, has been doing field work with baboons and highly technical neurological research in the laboratory for more than thirty years. He is a professor of neurology and biology at Stanford University, and a research associate with the Institute of Primate Research at the National Museum of Kenya. Robert Sapolsky is an author of 4 books: $A$ Primate's Memoir; The Trouble with Testosterone; Why Zebras Don't Get Ulcers; and Other Essays on our Lives as Animals. He is now working on a book to be titled: Behave: The Biology of Humans at Our Best and Worst. The lecture he gave during the pre-conference was about the last book he is working on. He reviewed the biology - considering everything from the events in the nervous system one second before the behavior occurs to the millions of years of evolutionary pressures that have shaped us as a species - of humans at their most pro- and most antisocial. He discussed that despite the fact that all species are unique, humans are more unique than others in a way that they can harm each other, or be compassionate and protective of each other.

Another interesting pre-conference keynote was presented by David Whyte, who is an author of eight books of poetry and four books of prose. He holds a degree in Marine Zoology, lived and worked as naturalist guide in the Galapagos Islands, and led anthropological and natural history expeditions in the Andes, Himalayas, and Amazon. He currently is an Associate Fellow at Said Business School at the University of Oxford. The lecture he presented at a conference was called: Solace: The Art of Asking the Beautiful Question, and explored the discipline of finding and asking the questions that help us re-imagine ourselves, our world and our part in it, questions that work to reshape our identities, helping us to become larger, more generous and more courageous.

The first day of the conference started very intensely including workshops and lectures in different rooms from 8 am till $7 \mathrm{pm}$. My day started with a workshop that drew my attention because of the sensitive topic it was covering. The workshop was held by Scott Miller, PhD, and was called "How Psychotherapy Lost its Magic (And What It Can Do to Get It Back”. Scott Miller, earned his PhD degree in counseling psychology at the University of Utah, and is a co-founder of the International Center for the Clinical Excellence and the Institute for the Study of Therapeutic Change. Dr. Miller conducts workshops and trainings all over the world, helping hundreds of agencies and organizations, both public and private, to achieve excellent results. In his workshop, he discussed why the overall effectiveness of psychotherapy over the years has not changed a single percentage point. Despite the fact that, presently, hundreds of treatment approaches exist, each claiming to contain ingredients essential to therapeutic success, clinicians tend to get worse and worse after the years of applying psychotherapy. Therefore, the 
majority of people who could benefit from psychotherapy, choose never to set foot in a therapist's office, or never come back after the first session. Dr. Miller proposed that the reason for this is that the therapists are out of touch with most people, because all they tend to focus on are thoughts, behaviors, feelings, and brain chemistry. Maybe what the field of psychotherapy is missing is "magic". He offered three steps for bringing enchantment/magic to psychotherapy which are: a) to explore their clients' beliefs in order to understand if those beliefs are barriers to healing; b) to enter people's reality and be with them in their beliefs; and c) to embody magic in healing traditions instead of trying to get rid of it.

The next keynote I want to discuss was held by Jeffrey Zeig and Sue Johnson, and they presented the essence of Salvador Minuchin's thinking and practice over 60 years. Jeffrey Zeig is the founder and director of the Milton H. Erickson Foundation, and the architect of The Evolution of Psychotherapy Conferences, The Brief Therapy Conferences, and the International Congresses on Ericksonian Approaches to Hypnosis and Psychotherapy. He has edited, co-edited, authored or coauthored more than 20 books on psychotherapy that appear in fourteen foreign languages. Sue Johnson is the developer of Emotionally Focused Therapy (EFT) and a Professor of Emeritus of Psychology, University of Ottawa, Distinguished Research Professor at Alliant University in San Diego, and Director of the International Centre for Excellence in Emotionally Focused Therapy. The lecture they gave was of special importance because it was dedicated to Salvador Minuchin, one of the most prominent names in psychology, who passed away few weeks before the conference. Salvador Minuchin was a contemporary psychiatrist who helped develop family therapy and pioneered the field of structural family therapy. In 2007, a survey of 2,600 psychology practitioners named Minuchin as one of the ten most influential therapists of all times. He has been a Research Professsor of Psychiatry at New York University, and Professor of Child Psychiatry and Pediatrics at University of Pennsylvania. Salvador Minuchin was a regular attendee of the Evolution of Psychotherapy Conferences, and was scheduled to attend the $8^{\text {th }}$ conference also. However, due to his sudden death, he couldn't attend the conference, and his granddaughter presented the speech he prepared for the conference instead of him. The videos of Minuchin's therapies was shown to the audience, and later Jeffrey Zeig and Sue Johnson discussed the therapeutic process, and deconstructed the complexity of his artistry into simple techniques that can be used by therapists of different orientations. Minuchin was criticized by Sue Johnson for sometimes not relating to the emotions observed in his therapies.

The other workshop I want to specifically mention is a workshop on "ADHD: The 7 Clinical Types", provided by Daniel Amen, a double boardcertified psychiatrist, multiple NY Times bestselling author, founder of Amen Clinics and brain imaging pioneer. The Washington Post has called Dr. Amen "America's most popular psychiatrist" because of his popular clinics which have 
over 4,000 patient visits a month and has the world's largest database of functional brain scans relating to behavior, totaling over 130,000 scans on patients from 111 countries. In his workshop, Dr. Amen discussed seven subtypes of ADHD which are: 1) classic $\mathrm{ADD}, 2$ ) inattentive $\mathrm{ADD}, 3)$ overfocused $\mathrm{ADD}, 4)$ temporal lobe $\mathrm{ADD}, 5)$ limbic $\mathrm{ADD}, 6)$ ring of fire $\mathrm{ADD}$, and 7) anxious ADD; and pointed out that knowing individual's ADD type is essential to getting the right help. Different symptoms of ADD were discussed, and the effect of exercising, food diet, supplements, digital overexposure, medicine were analyzed. $\mathrm{He}$ also closely examined the five hallmark symptoms of ADD, which include: short attention span, distractibility, disorganization, procrastination, and poor internal supervision.

Dr. Daniel Amen also engaged in a debate with Dr. Michael Yapko discussing the different approaches to depression, which are biological, psychological, social, and spiritual. Michael Yapko is internationally recognized for his work in clinical hypnosis, and has presented his work in more than 30 countries. He has authored 15 books and won many awards for his work. Daniel Amen and Michael Yapko compared and contrasted their viewpoints about depression, addressing such topics as the merits of neuroimaging in depression, causes and types of depression, the role of diet and use of supplements in treatment, and the reason why not all psychotherapies are equally effective in promoting recovery. While Daniel Amen compared depression to brain health, Michael Yapko argued that the risk factors were primarily social.

The conference also included different workshops and debates on specific psychotherapy types and also their comparison and use in the treatment of different psychological disorders. One of those interesting debates took place between Christine Padesky and Jack Kornfield, where they discussed the similarities and differences between Cognitive Behavioral Therapy and Buddhism/Mindfulness. Christine Padesky is a leading Cognitive Behavior Therapy (CBT) innovator, and along with Kathleen Mooney, she created Strengths-Based CBT, which helps clients construct new beliefs and behavioral strategies in order to improve overall functioning and relationships. She is co-author of five books, including Mind Over Mood, and with over a million copies sold in 23 languages, Mind Over Mood was named the most influential CBT book of all time by the British Association of Behavioral and Cognitive Therapies. Jack Cornfield was trained as a Buddhist Monk in the monasteries of Thailand, India, and Burma. He has taught meditation internationally since 1974 and is one of the key teachers to introduce Buddhist Mindfulness practice to the west. Jack Kornfield holds a $\mathrm{PhD}$ in clinical psychology and is an author of many books which have been translated into 22 languages. Padesky discussed that the therapists should use people's strength to change them and help them grow and develop positive qualities, which often people are not aware of. In their model they help people to develop and facilitate self-awareness and awareness of others. Mindfulness is similar to CBT in a way that it also helps to release unhealthy strategies and gain healthy strategies. 
Buddhist training does more than offer purely rational replacement of inaccurate thought patterns. Buddhist approach can be called "behaviorism with heart" and it enlists the power of a larger, benevolent intention.

One of the captivating debates which attracted the interest of a very large audience was by Esther Perel and Marilyn Yalom. They discussed the issue of masculinity and femininity, the history of it and how those are perceived nowadays. Esther Perel is a Belgian psychotherapist who is notable for studying the tension between the need for security (love, belonging, and closeness) and the need for freedom (erotic desire, adventure and distance) in human relationships. She has her private practice in New York City for over 30 years. She is the author of several books such as Mating Captivity and The State of Affairs. Marilyn Yalom who is a senior scholar at the Clayman Institute for Gender Research at Stanford University, is also wife of Irvin Yalom. She is the author of a lot of books which have been translated into 20 languages. Her book How the French Invented Love, was short-listed for the Phi Beta Kappa Gauss literary award and for the American Library in Paris book award, in 2013. The dialogue between Esther Perel and Marilyn Yalom explored the challenges that men and women face in assuming trait and roles of the opposite gender. They discussed how masculinity and femininity evolved throughout the history, so that by now, in the Western world, women are expected to use their brains as well as their hearts and men are encouraged to assume some of the roles previously allotted exclusively to women. One of the ideas was that we are edging toward androgynous definition of gender and a multiplicity of gender identities.

Tipper Gore, once named one of the "Ten Most Admired Women in the World", delivered a beautiful speech I want to discuss last in this article. She presented a keynote speech on the topic of "Mental Health and World We Seek". Tipper Gore was the second lady of United States during Bill Clinton's time, wife of $\mathrm{Al}$ Gore: $45^{\text {th }}$ vice-president of United States, psychology graduate, photographer, advocate for mental health, homelessness, violence in the media, and LGBT rights. In her speech she mentioned that the mental health community continues working to expand our understanding of the brain and to improve both the quality of and the access to treatment. She also discussed the role of those working with mental health in the critical challenges and mentioned that making mental health priority not only benefits people with mental illness, but also society at large.

The Evolution of Psychotherapy Conference managed to fit in many different topics of psychology and other sciences in its program. Topics covering CBT, DBT, mindfulness, Buddhism, positive psychology, child psychology, hypnosis, neuropsychology, family psychology and many others were analyzed thoroughly. These fields were examined closely starting from the history, past practices, innovations and changes, and also future practices. Witnessing these 
seminars and debates from the prominent scientists and even creators of the theories and approaches themselves, having a chance to discuss everything with large pool of psychologists from all over the world makes Evolution of Psychotherapy Conference especially important and memorable.

It was a pleasure for me to introduce Khazar University Psychology Department at the Evolution of Psychotherapy conference and build collaborations with worldly renowned psychologists. 